\section{Prediction of Development of Asiatic Lilies Based on Air Temperature and Thermal Units}

\author{
J. Steininger ${ }^{1}$ and C.C. Pasian ${ }^{2}$ \\ Department of Horticulture and Crop Science, The Ohio State University, \\ Columbus, $\mathrm{OH} 43210$
}

Additional index words. heat units, base temperature, degree days, crop timing, Lilium spp.

\begin{abstract}
Butter Pixie' and 'Horizon' Asiatic lilies (Lilium spp.), were grown at several temperatures. The phenological events of visible shoot (VS), visible flower bud (VB), and open flower (OF) were recorded daily. Based on these events, phenophases from VS to VB (VS:VB), from VB to OF (VB:OF), and from VS to OF (VS:OF) were defined. Daily rates of development to complete a phenophase increased with temperature. Nonlinearity was obvious for all phenophases around $25^{\circ} \mathrm{C}$ for 'Horizon' and $27^{\circ} \mathrm{C}$ for 'Butter Pixie'. A piece-wise linear regression change point model was fitted to each dataset. The base temperature $\left(T_{b}\right)$, the temperature at which the nonlinearity occurred $\left(T_{i}\right)$, and the temperature for fastest development $\left(T_{0}\right)$ could then be determined. $T_{b}$ for the phenophase VS : OF was $-\mathbf{0 . 4}{ }^{\circ} \mathrm{C}$ for 'Butter Pixie' and $3.0^{\circ} \mathrm{C}$ for 'Horizon'. $\mathrm{T}_{\mathrm{i}}$ for 'Butter Pixie' was $25.7^{\circ} \mathrm{C}$ for VB:OF and $26.1^{\circ} \mathrm{C}$ for the phenophase VS:OF. However, $T_{\text {i }}$ for ''Horizon' was found only for the phenophase VS:OF. To complete the phenophase VS:OF, 1102.2 degree days $\left({ }^{\circ} \mathrm{Cd}\right)$ were predicted necessary for 'Butter Pixie' and 833.2 ${ }^{\circ} \mathrm{Cd}$ for 'Horizon'. Predicted time of events was compared with observed values. Subdividing VS:OF into VS:VB and VB:OF and using their respective $T_{b}$ and TU reduced the average prediction error from 2.13 to $1.87 \mathrm{~d}$ for 'Butter Pixie' and from 2.39 to $\mathbf{1 . 8 6}$ days for 'Horizon'.
\end{abstract}

Asiatic lilies (Lilium spp.) are one of the nine primary groups of commercial hybrid lilies and contribute numerous cultivars with a wide variety of flower shapes, sizes, and colors. Traditionally, Asiatic lilies were grown as cut flower crops. Through breeding, however, short stemmed cultivars are now successfully used for pot plant forcing. Most cultivars can be stored at sub-freezing temperatures of $-1.8^{\circ} \mathrm{C}$ for extended periods. Hence, many Asiatic lily cultivars may be produced year-round as long as temperatures and light levels can be controlled (Beck, 1988; De Hertogh, 1996).

For many years researchers have investigated the effects of temperature on plant development. The quantification of environmental variables and the formulation of mathematical models have provided growers of agronomic crops with techniques for predicting maturity of a wide range of commodity crops such as wheat (Triticum aestivum L.), maize (Zeamays L.), and soybeans (Glycine max Merrill) and various vegetables (Arnold, 1959; Yang et al., 1995). Similarly, the effect of environmental variables and its modeling were studied on Easter lilies (Fisher et al., 1997; Lieth and Carpenter, 1990), dahlias (Brodum and Royal, 1993), Senecio $\times$ hybridus (Larsen, 1988) and

Received for publication 27 Mar. 2002. Accepted for publication 9 Jan. 2003. Salaries and research support provided by state and federal funds appropriated to the Ohio Agricultural Research and Development Center, The Ohio State Univ. This research was supported in part by a grant of the Ohio Floriculture Foundation.

${ }^{1}$ Graduate Research Associate.

${ }^{2}$ Associate Professor. To whom reprint requests should be addressed. containers were filled to a height of $\approx 3 \mathrm{~cm}$ with potting medium before planting the bulb. Once the bulb was placed on top of this initial layer of media, the container was then filled. This procedure ensured that all bulbs were located at approximately the same height in the medium and had sufficient medium covering the bulb to allow the plants to develop stem roots (De Hertogh, 1996).

Bulbs were planted, containers tagged, and after watering moved into four different greenhouse compartments for temperature treatments. A computerized environmental control system of the greenhouse was utilized to maintain temperatures within certain limits in the four compartments. Low temperature observations were only made from November throughout April each year in a compartment that had a temperature set point of $5^{\circ} \mathrm{C}$. The other treatments were conducted simultaneously in all compartments year-round and the temperature set points for these compartments were $15{ }^{\circ} \mathrm{C}, 25^{\circ} \mathrm{C}$, and $30{ }^{\circ} \mathrm{C}$. The recorded air temperatures were used in all calculations because actual temperatures varied substantially from set points, especially during the summer months.

Data loggers (On-site Weather Logger, EME Systems, Berkeley, Calif.) were used to measure and log average hourly air temperature. Copper-constantan thermocouples were connected to data loggers and used as temperature probes at $\approx 5 \mathrm{~cm}$ above the canopy. Each thermocouple was protected from direct sunlight with an aluminum foil shield.

Plant inspections were conducted daily at $1700 \mathrm{HR}$ and the development of plants was recorded. Observations were based on visual examination of the plant. The definition of each developmental stage was adapted from previous work (Pasian and Lieth, 1994,1996; Steininger et al., 2002). Asiatic lily development consists of phases marked by specific, observable phenological events (Table 1). The phenophases selected for analysis were from visible shoot to open flower (VS:OF). Further, VS:OF was divided into visible shoot to visible flower bud (VS:VB) and visible flower bud to open flower (VB:OF) (Table 1).

Observations were made on 282 'Butter Pixie' and 284 'Horizon' plants on six crops grown from mid-1994 through 1997. As a consequence, plants were grown under different photoperiods and light integral conditions (different seasons).

Plants were fertilized with $20 \mathrm{~N}-4.3 \mathrm{P}-$ 16.7K (Scotts-Sierra Hort. Products Co., Marysville, Ohio) liquid fertilizer at a concentration of $1 \mathrm{~g} \cdot \mathrm{L}^{-1}$. Plants were irrigated by hand as needed.

Estimation of base temperatures. Daily rates of development $(\mathrm{R})$ reflecting the fractional amount of development per day were

Table 1. Definitions of developmental events of Asiatic lilies.

\begin{tabular}{ll}
\hline Event & Description of developmental events \\
\hline VS & $\begin{array}{c}\text { Visible Shoot: the day on which the shoot broke through the surface of the } \\
\text { potting media and became visible }\end{array}$ \\
VB & $\begin{array}{l}\text { Visible Flower Bud: the day the flower buds become visible } \\
\text { OF }\end{array}$ \\
\hline
\end{tabular}


estimated by calculating the reciprocal of the number of days a plant required to complete a given phenophase. Rates of development were related to the average air temperatures $T_{j}$ with the following equation:

$R= \begin{cases}0 & \ldots \text { if } \mathrm{T}_{\mathrm{j}} \leq \mathrm{T}_{\mathrm{b}} \\ \mathrm{a}_{0}+\mathrm{b}_{0} \times \mathrm{T}_{\mathrm{j}} & \ldots \text { if } \mathrm{T}_{\mathrm{b}}<\mathrm{T}_{\mathrm{j}} \mathrm{T}_{\mathrm{i}} \\ \mathrm{a}_{1}+\mathrm{b}_{1} \times \mathrm{T}_{\mathrm{j}} & \ldots \text { if } \mathrm{T}_{\mathrm{j}}>\mathrm{T}_{\mathrm{i}}\end{cases}$

where $\mathrm{T}_{\mathrm{b}}$ is the base temperature, $\mathrm{T}_{\mathrm{i}}$ is the temperature at which the slope changes (Steininger et al., 2002). If the slope of the regression line when $T_{j}>T_{i}$ is negative, $T_{i}$ represents the optimum temperature for development $\left(\mathrm{T}_{\mathrm{o}}\right)$. The parameters $\mathrm{a}_{0}, \mathrm{a}_{1}, \mathrm{~b}_{0}$, and $\mathrm{b}_{1}$ are empirically determined and may be specific to a genotype and a given developmental stage (Jamieson et al., 1995; Summerfield et al., 1991). Base temperatures were calculated using the formula:

$$
\mathrm{T}_{\mathrm{b}}=-\mathrm{a}_{0} \cdot \mathrm{b}_{0}^{-1}
$$

To determine whether each data set presented nonlinearity in temperature response $\left(T_{i}\right)$, two linear regression models were fitted simultaneously. That amounted to a nonlinear piece-wise least squares regression with random change point. All fittings were done with the $\mathrm{S}+($ Statistical Sciences, Seattle) statistical package. Because of nonhomogeneity (nonconstant variance), weighted least squares were used with weights inversely proportional to the variances. $T_{i}$ was calculated using the formula:

$$
\mathrm{T}_{\mathrm{i}}=\left(\mathrm{a}_{0}-\mathrm{a}_{1}\right) \cdot\left(\mathrm{b}_{1}-\mathrm{b}_{0}\right)^{-1}
$$

where $\mathrm{a}_{0}$ and $\mathrm{a}_{1}$ represent the $\mathrm{y}$ intercepts and $b_{1}$ and $b_{0}$ represent the slopes of the two fitted lines. The statistical procedure bootstrap was used to obtain SEs for the estimates and confidence intervals for the temperature limits (Efron and Tibshirani,1993).

Thermal units calculation. In order to consider potential nonlinearities of the data (i.e. decreasing rates of developments with increasing temperatures above a given temperature), thermal units were calculated using an extension of the traditional thermal unit formula

$\mathrm{TU}=$

$\sum \begin{cases}\max \left(\mathrm{T}_{\mathrm{j}}-\mathrm{T}_{\mathrm{b}}, 0\right\} \Delta \mathrm{t}_{\mathrm{j}} & \ldots \text { if } \mathrm{T}_{\mathrm{j}} \leq \mathrm{T}_{\mathrm{i}} \\ \max \left(\mathrm{T}_{\mathrm{i}}-\mathrm{T}_{\mathrm{b}}+\mathrm{k} \times\left(\mathrm{T}_{\mathrm{j}}-\mathrm{T}_{\mathrm{b}}\right), 0\right\} \Delta \mathrm{t}_{\mathrm{j}} \ldots \text { if } \mathrm{T}_{\mathrm{j}} \geq \mathrm{T}_{\mathrm{i}}\end{cases}$

developed by Steininger et al. (2002):

where TU are the thermal units accumulation with units of degree day $\left({ }^{\circ} \mathrm{Cd}\right), \mathrm{k}$ is the ratio $(<1)$ of the slope of the regression line at temperatures higher than $T_{i}$ and the slope of the regression line at temperatures lower than $T_{i}$ and $t$ is time. The function for $T_{j}<T_{i}$ is the typical thermal units formula.

TU accumulated during the phenophases VS:VB, VB:OF, and VS:OF of each plant were calculated using equation [2]. An average was then computed for each of these phenophases, yielding the average number of thermal units needed to reach the events VB or OF. Using these averages, the data were re-analyzed to determine the magnitude of the discrepancy (in number of days) between the occurrences of these average thermal unit thresholds and the observed date of the event.

Predictions were tested using two methods: 1) average method, where only the $T_{b}$ and TU summations for the entire phenophase VS:OF were used, and 2) additive method, where $T_{b}$ and TU summations for each of the phases VS:VB and VB:OF were used. In the additive method, the predicted dates of VB for the phenophase VS:VB were used in turn as the "observed" dates of VB for calculation of OF occurrence. The mean error of prediction was calculated by averaging the absolute values of the difference between observed date and predicted date.

\section{Results}

Rates of development for Asiatic lilies increased with increasing mean air temperatures (Fig. 1). For all phenophases, a nonlinearity was obvious at $\approx 25{ }^{\circ} \mathrm{C}$ for 'Horizon' and $27^{\circ} \mathrm{C}$ for 'Butter Pixie'. For the phenophase VS:VB of 'Butter Pixie' and 'Horizon', increasing temperatures beyond $28.7{ }^{\circ} \mathrm{C}$ and $25.2{ }^{\circ} \mathrm{C}$, respectively, resulted in decreasing rates of development (Fig. 1). A high variability in development rates was observed for the phenophase VS:VB of both cultivars.

$\mathrm{T}_{\mathrm{b}}$ is represented by the intersection of the regression line for $\mathrm{T}_{\mathrm{j}}<\mathrm{T}_{\mathrm{i}}$ and the $\mathrm{x}$-axis (Fig. 1). $\mathrm{T}_{\mathrm{b}}$ for the three phenophases of 'Butter Pixie' were negative $\left(-1.0,-2.6\right.$, and $\left.-0.4{ }^{\circ} \mathrm{C}\right)$ while they were positive $\left(1.9,3.6\right.$, and $\left.3.0^{\circ} \mathrm{C}\right)$ for 'Horizon' (Table 2).

'Butter Pixie' had a temperature for fastest development $\left(\mathrm{T}_{\mathrm{o}}\right)$ for the phenophase VS:VB (Fig. 1), but not for phenophase VB:OF where only nonlinearity $\left(T_{i}\right)$ was evident. In contrast, $T_{0}$ was found for both phases, VS:VB and VB:OF for 'Horizon' (Fig. 1). The

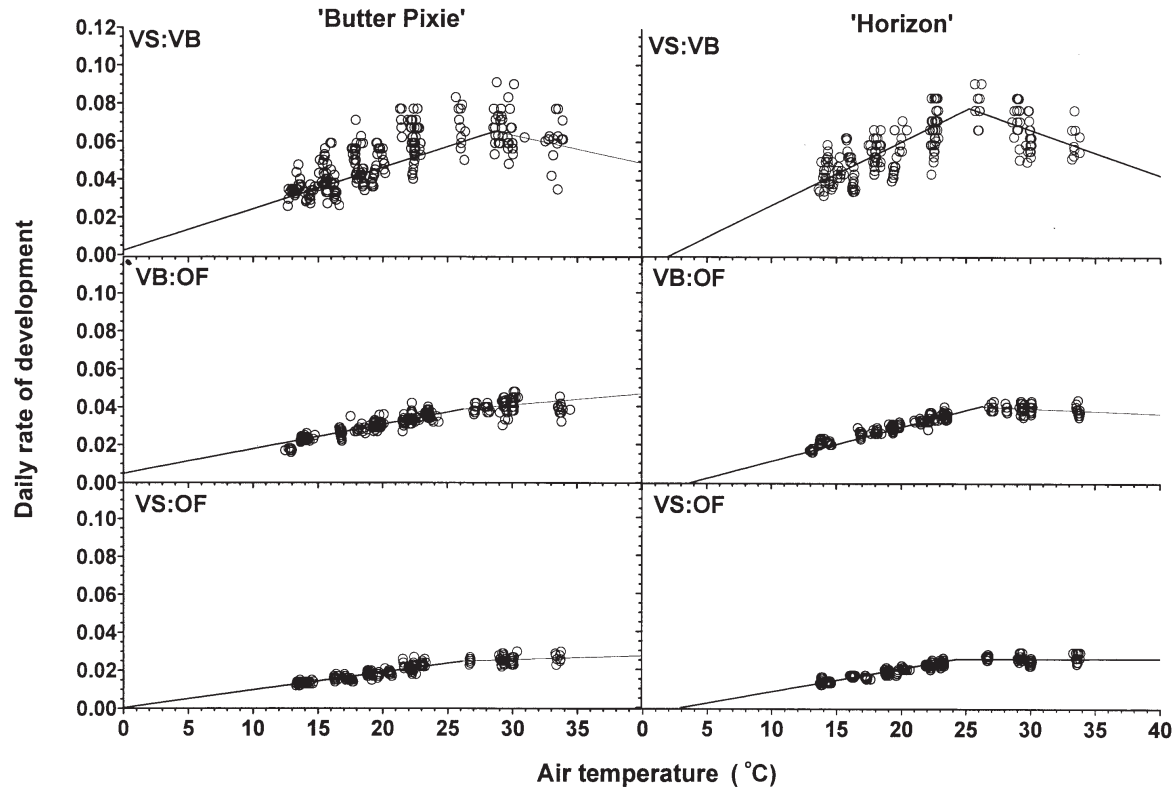

Fig. 1. Daily rates of development for the phenophases VS:VB, VB:OF and VS:OF of 'Butter Pixie' and 'Horizon' Asiatic lilies as a function of air temperature. Symbols represent observations of individual plants. Lines represent the statistical fitting of the two-phase model. VS = visible shoot; VB $=$ visible flower bud; and $\mathrm{OF}=$ open flower. decrease in development rate (negative slope) above $28.7^{\circ} \mathrm{C}$ for the phenophase VS:VB of 'Butter Pixie' was $55 \%$ of the rate of increase at temperatures below $\mathrm{T}_{\mathrm{o}}$ (Table 2). In contrast, when the temperature was above 25.7 ${ }^{\circ} \mathrm{C}$ for phenophase VB:OF, the development rate increase (still a positive slope) was $47 \%$ of the increase below $\mathrm{T}$. The rate of development for 'Horizon' above $25.2{ }^{\circ} \mathrm{C}\left(\mathrm{T}_{\mathrm{o}}\right)$ was very similar to the rate of increase below such temperature for the phenophase VS: VB(Table $2)$. For the phenophase VB:OF, development rates declined only by $20 \%$ (Table 2 ).

'Butter Pixie' required more TUs to complete the phenophase VS:OF than 'Horizon': $1102.2{ }^{\circ} \mathrm{Cd} \pm 86.4{ }^{\circ} \mathrm{Cd}$ vs. $833.2{ }^{\circ} \mathrm{Cd} \pm$ $60.6^{\circ} \mathrm{Cd}$, respectively (Table 2 ). This is consistent with the observation that 'Horizon' blooms earlier than 'Butter Pixie' when grown in the same environment.

The average error of prediction for 'Butter Pixie' $( \pm 2.13 \mathrm{~d})$ was slightly smaller than for 'Horizon' $( \pm 2.39 \mathrm{~d})$ when predicted dates were calculated using the average method. When the additive method was used, the average error of prediction was the same $( \pm 1.86 \mathrm{~d})$ for both cultivars (Table 3 ). As indicated by their standard rate of deviation (SD), variability was large. The model can be considered unbiased because the prediction error is similar at any time of the year regardless of environmental conditions, i.e. natural light levels, photoperiod, and varying temperature regimes (Fig. 2).

\section{Discussion}

These results are in agreement with other reports showing that ambient air temperature has a strong effect on plant development (Baker and Gallagher, 1983; Grace, 1988; Karlsson et al., 1991). For both lily cultivars, either a $T_{0}$ or $T_{i}$ was found (Fig. 1) indicating that development is more sensitive to high 
Table 2. Parameters $\left(a_{0}, b_{0}, a_{1}\right.$, and $\left.b_{1}\right)$ of linear regression models fitted to rates of development $\left(\mathrm{d}^{-1}\right)$ as a function of temperature $\left(T_{j}\right)$, base temperature $\left(T_{b}\right)$, temperature at which the nonlinearity occurs $\left(T_{j}\right)$, ratio of slopes (k), and thermal unit accumulations (TU) and their SD for each phenophase of 'Butter Pixie' and 'Horizon'Asiatic lilies. VS = visible shoot; VB = visible flower bud; OF = open flower.

\begin{tabular}{|c|c|c|c|c|c|c|c|c|c|}
\hline \multirow[b]{2}{*}{ Phenophase } & \multicolumn{2}{|c|}{ Estimates for $T_{j} \leq T_{i}$} & \multicolumn{2}{|c|}{ Estimates for $\mathrm{T}_{\mathrm{j}}>\mathrm{T}_{\mathrm{i}}$} & \multirow[b]{2}{*}{$\begin{array}{c}\mathrm{T}_{\mathrm{b}} \\
\left({ }^{\circ} \mathrm{C}\right)\end{array}$} & \multirow[b]{2}{*}{$\begin{array}{c}\mathrm{T}_{\mathrm{i}} \\
\left({ }^{\circ} \mathrm{C}\right)\end{array}$} & \multirow[b]{2}{*}{$\mathrm{k}$} & \multirow[b]{2}{*}{$\begin{array}{c}\mathrm{TU} \\
\left({ }^{\circ} \mathrm{Cd}\right)^{\mathrm{z}}\end{array}$} & \multirow[b]{2}{*}{$\begin{array}{c}\mathrm{SD} \\
\left({ }^{\circ} \mathrm{Cd}\right)\end{array}$} \\
\hline & $\begin{array}{c}a_{0} \\
\left(d^{-1}\right)\end{array}$ & $\begin{array}{c}\mathrm{b}_{0} \\
\left(\mathrm{~d}^{-1} \cdot \mathrm{C}^{-1}\right)\end{array}$ & $\begin{array}{c}\mathrm{a}_{1} \\
\left(\mathrm{~d}^{-1}\right)\end{array}$ & $\begin{array}{c}\mathrm{b}_{1} \\
\left(\mathrm{~d}^{-1} \cdot \mathrm{C}^{-1}\right)\end{array}$ & & & & & \\
\hline \multicolumn{10}{|c|}{ Butter Pixie } \\
\hline VS : VB & -0.0019 & 0.0027 & 0.1071 & -0.0015 & -1.0 & 28.7 & -0.55 & 443.6 & 84.6 \\
\hline $\mathrm{VB}: \mathrm{OF}$ & 0.0049 & 0.0013 & 0.0229 & 0.0006 & -2.6 & 25.7 & 0.47 & 742.5 & 46.0 \\
\hline VS : OF & 0.0012 & 0.0009 & 0.0192 & 0.0002 & -0.4 & 26.1 & 0.24 & 1102.2 & 86.4 \\
\hline \multicolumn{10}{|c|}{ Horizon } \\
\hline VS : VB & 0.0113 & 0.0024 & 0.1381 & -0.0024 & 1.9 & 25.2 & -0.99 & 305.1 & 55.8 \\
\hline $\mathrm{VB}: \mathrm{OF}$ & -0.0068 & 0.0019 & 0.0471 & -0.0003 & 3.6 & 25.7 & -0.20 & 539.1 & 34.5 \\
\hline VS : OF & 0.0023 & 0.0009 & 0.0253 & 0.00001 & 3.0 & 24.2 & 0.01 & 833.2 & 60.6 \\
\hline
\end{tabular}

${ }^{2}$ Degree day $\left({ }^{\circ} \mathrm{Cd}\right)$.

Table 3. Number of open flower predictions within each prediction error category [days (d)] and its percentage for 'Butter Pixie' and 'Horizon'. Predicted were calculated using the average and additive methods. The overall average error of prediction (bottom) was calculated using the absolute value of each error of prediction.

\begin{tabular}{|c|c|c|c|c|c|c|c|c|}
\hline \multirow{3}{*}{$\begin{array}{l}\text { Error } \\
\text { Category (d) }\end{array}$} & \multicolumn{4}{|c|}{ Butter Pixie } & \multicolumn{4}{|c|}{ Horizon } \\
\hline & \multicolumn{2}{|c|}{ Average method } & \multicolumn{2}{|c|}{ Additive method } & \multicolumn{2}{|c|}{ Average method } & \multicolumn{2}{|c|}{ Additive method } \\
\hline & Predicted & $(\%)$ & Predicted & $(\%)$ & Predicted & $(\%)$ & Predicted & $(\%)$ \\
\hline $\pm 0-0.99$ & 84 & 29.8 & 109 & 38.8 & 65 & 22.9 & 82 & 28.9 \\
\hline $\pm 1-1.99$ & 66 & 23.4 & 62 & 21.9 & 71 & 25.0 & 87 & 30.6 \\
\hline $\pm 2-2.99$ & 58 & 20.6 & 44 & 15.6 & 52 & 18.3 & 62 & 21.9 \\
\hline $\pm 3-3.99$ & 40 & 14.2 & 39 & 13.8 & 44 & 15.5 & 34 & 11.9 \\
\hline $\pm 4-4.99$ & 23 & 8.2 & 19 & 6.7 & 30 & 10.6 & 12 & 4.2 \\
\hline $\pm 5-5.99$ & 5 & 1.8 & 5 & 1.8 & 18 & 6.3 & 6 & 2.1 \\
\hline $\pm 6-6.99$ & 4 & 1.4 & 2 & 0.7 & 3 & 1.1 & 1 & 0.4 \\
\hline $\pm 7-7.99$ & 1 & 0.3 & 2 & 0.7 & 0 & 0 & 0 & 0 \\
\hline $\pm 8-8.99$ & 0 & 0 & 0 & 0 & 0 & 0 & 0 & 0 \\
\hline $\pm 9-9.99$ & 1 & 0.3 & 0 & 0 & 1 & 0.3 & 0 & 0 \\
\hline Total & 282 & 100 & 282 & 100 & 284 & 100 & 284 & 100 \\
\hline
\end{tabular}

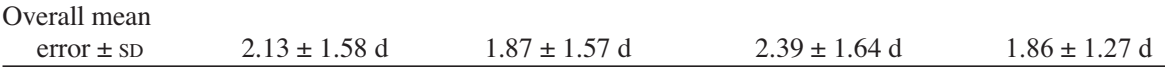

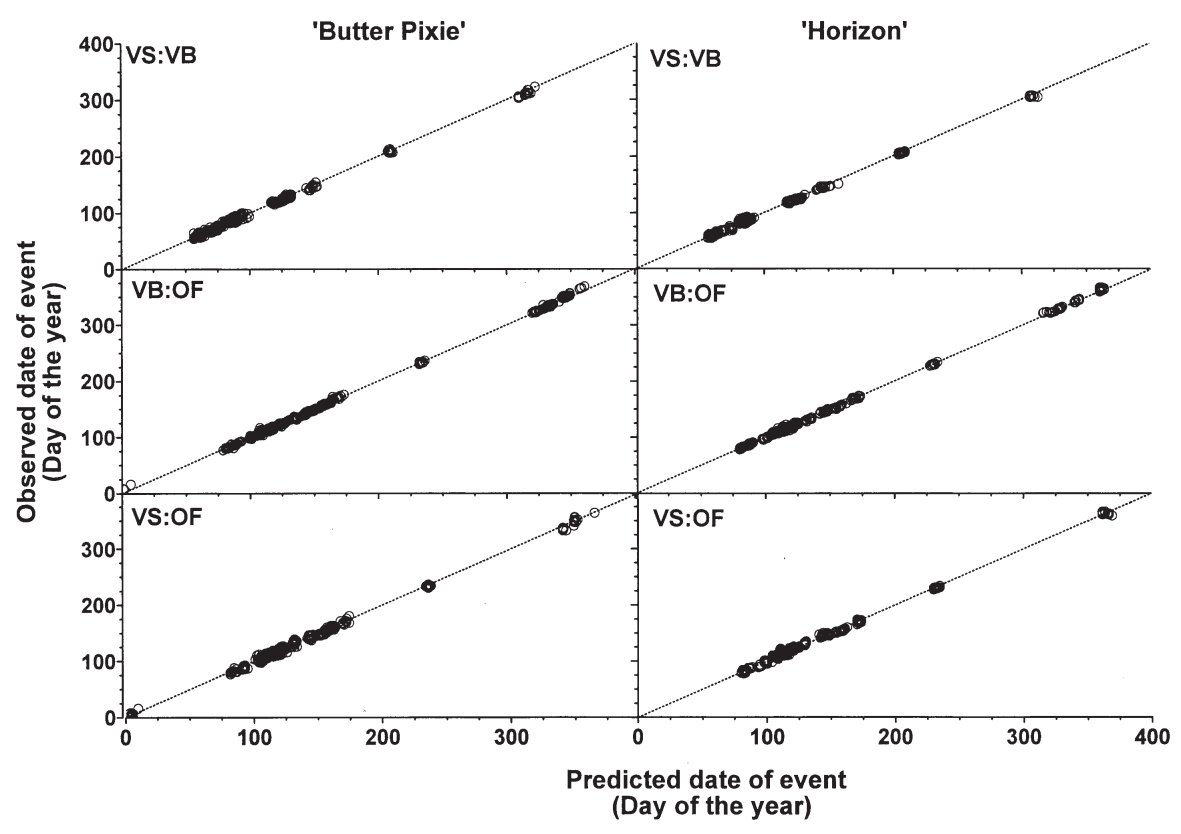

Fig. 2. Predicted vs. observed days of phenophase completion for VS:VB, VB:OF, and VS:OF of 'Butter Pixie' and 'Horizon' Asiatic lilies. The dotted line represents $y=x$. VS $=$ visible shoot; $\mathrm{VB}=$ visible flower bud; and $\mathrm{OF}=$ open flower. temperatures than miniature roses where no $\mathrm{T}_{\mathrm{o}}$ or $\mathrm{T}_{\mathrm{i}}$ were found even after growing the plants at high temperatures (Steininger, et al., 2002). Brodum and Heins (1993) found that the optimal temperatures for dahlias for the stages pinch-to-visible-bud and from visible-bud-toflower were $20.3^{\circ} \mathrm{C}$ and $22.0^{\circ} \mathrm{C}$ respectively. These values are lower than the temperature values at which nonlinearity $\left(\mathrm{T}_{\mathrm{i}}\right)$ occurred for both Asiatic lilies studied in this work: $28.7^{\circ} \mathrm{C}$ and $25.7^{\circ} \mathrm{C}$ for 'Butter Pixie' and $25.2^{\circ} \mathrm{C}$ and $25.7^{\circ} \mathrm{C}$ for 'Horizon'(Table 1$)$.

Although decreasing rates of development with increasing temperatures are always mentioned in the published literature, there are few examples demonstrating such plant response to temperature (e.g. Brodum and Heins, 1993; Karlsson et al., 1991; Slafer and Rawson, 1995). Development rates as a function of mean air temperature presented in this work are among those few that allow the determination of an optimal temperature for development $\left(\mathrm{T}_{\mathrm{o}}\right)$. The maximum temperature for development still remains elusive. No published report was found that showed data from which this cardinal temperature could have been estimated. All our attempts to grow plants at temperatures at, or above, $35^{\circ} \mathrm{C}$ resulted in seriously damaged (i.e. chlorotic, no growth, etc.) or dead plants. We speculate that developmental rates at such high temperatures fall abruptly due to plant stress. Therefore, the assumption that the second phase of the model (above $\mathrm{T}_{\mathrm{o}}$ or $\mathrm{T}_{\mathrm{i}}$ ) is linear, would be only an approximation. The scope of use of this model is below $35^{\circ} \mathrm{C}$.

For different crops, $\mathrm{T}_{\mathrm{b}}$ can vary from $-1.9{ }^{\circ} \mathrm{C}$ for wheat (Triticum spp.) (Slafer and Rawson, 1995) to $15.5^{\circ} \mathrm{C}$ for cucumber (Cucumis sativus L.) (Perry et al., 1986). $\mathrm{T}_{\mathrm{b}}$ found in this work for Asiatic lilies fall at the low end of such temperature spectrum: -0.4 for 'Butter Pixie' and $3.0^{\circ} \mathrm{C}$ for 'Horizon'. These low $\mathrm{T}_{\mathrm{b}}$ support the observation that Asiatic lilies are tolerant of cool growing environments.

Overall, the error in prediction herein was small and model behavior was unbiased regarding time of the year of application. For Asiatic lilies, the additive method of prediction was superior to the average method. This is further evidence supporting previous hypotheses that shifting temperature limits and TU parameters can change during plant development (Slafer and Savin 1991; Slafer and Rawson, 1995; Wang, 1960). If these results are validated with an independent data set, this TU model can be used for greenhouse temperature manipulation and timing of Asiatic lilies. Although fastest temperatures for development of Asiatic lilies were determined in this work, the optimal temperature for plant growth and quality is most likely lower: plants grown for this research at temperatures close to $\mathrm{T}_{\mathrm{o}}$ were of poor commercial quality with respect to plant size and flower appearance.

\section{Literature Cited}

Arnold, C.Y. 1959. The determination and significance of the base temperature in a linear heat unit 
system. Proc. Am. Soc. Hort. Sci. 74:430-445.

Baker, C.K. and J.N. Gallagher. 1983. The development of winter wheat in the field. 2. The control of primordium initiation rate by temperature and photoperiod. J. Agr. Sci. 101:337-344.

Beck, R. 1988. Hybrid lily bulbs: Pot plant production Asiatic and Oriental hybrids. F. C. Gloeckner Co., Portland, Ore.

Brodum, J.J. and R.D.Heins. 1993. Modeling temperature and photoperiod effects on growth and development of dahlia. J. Amer. Soc. Hort. Sci. 118(1):36-42 .

De Hertogh, A.A. 1996. Holland bulb forcer's guide. The Intl. Flower-Bulb Centre, Hillegom, The Netherlands.

Del Pozo, A.H., J. Garcia-Huidobro, R. Novoa, and S. Villaseca. 1987. Relationship of base temperature to development of spring wheat. Expt. Agr. 23:21-30

Efron, B. and R.J. Tibshirani. 1993. An introduction to the bootstrap. Chapman \& Hall, New York.

Fisher, P.R., J.H. Lieth and R.D. Heins. 1997. Predicting variability in anthesis of Easter lily (Lilium longiflorum Thunb.) populations in response to temperature. Acta Horticulturae 456:117-124.

Grace, J. 1988. Temperature as a determinant of plant productivity, p. 91-101. In: S.P. Long and
F.I. Woodward (eds.). Plants and temperature. Biologists Limited, Cambridge, U.K.

Jamieson, P.D., I.R. Brooking, J.R. Porter, and D.R Wilson. 1995. Prediction of leaf appearance in wheat: A question of temperature. Field Crops Res. 41:35-44.

Karlsson, M.G., R.D. Heins, J.O. Gerberick, and M.E. Hackmann. 1991. Temperature driven leaf unfolding rate in Hibiscus rosa-sinensis. Scientia Hort. 45:323-331.

Larsen, R., 1988. A dynamic model for prediction of developmental rate of the pot plant Senecio $\times$ hybridus Hyl. Rpt. 53. Dept. Hort. Sci. Swedish Univ. of Agr. Sci. Alnarp.

Lieth, J.H. and P. Carpenter. 1990. Modeling stem elongation and leaf unfolding of Easter lily during greenhouse forcing. Scientia Hort 44(1-2):149-162.

Pasian, C.C. and J.H. Lieth. 1994. Prediction of flowering rose shoot development based on air temperature and thermal units. Scientia Hort. 59:131-145.

Pasian, C.C. and J.H. Lieth. 1996. Prediction of rose shoot development: Model validation for the cultivar 'Cara Mia' and Extension to the cultivars 'Royalty' and 'Sonia'. Scientia Hort. 66:117-124.

Perry, K.B., T.C Whener, and G.L. Johnson. 1986.
Comparison of 14 methods to determine heat unit requirements for cucumber harvest. HortScience 21:419-423.

Slafer, G.A. and H.M. Rawson. 1995. Base and optimum temperatures vary with genotype and stage of development in wheat. Plant, Cell and Environ. 18:671-679.

Slafer, G.A. and R. Savin. 1991. Developmental base temperature in different phenological phases of wheat (Triticum aestivum). J. Expt. Bot. 42(241):1077-1082.

Steininger, C.C. Pasian and J.H. Lieth. 2002. Extension of a thermal unit model to represent nonlinearities in temperature response of miniature rose (Rosa 1. hybrids) development. J. Amer. Soc. Hort. Sci. 127(3):349-354.

Summerfield, R.J., E.H. Roberts, R.H. Ellis, and R.J.Lawn. 1991. Towards the reliable prediction of time to flowering in six annual crops. I. The development of simple models for fluctuating field environments. Expt. Agr. 27:11-31.

Wang, J.Y. 1960. A critique of the heat unit approach to plant response studies. Ecology 41(4):785-789.

Yang, S., J. Logan, and D.L. Coffey. 1995. Mathematical formulae for calculating the base temperature for growing degree days. Agr. and Forest Meteorol. 74:61-74. 